\title{
FONTES E DOSES DE NITROGÊNIO E A QUALIDADE DOS FRUTOS DO MAMOEIRO'
}

\author{
Cláudia Sales Marinho; ${ }^{2 *}$ Mayron Augusto Borges de Oliveira ${ }^{3}$; Pedro Henrique Monnerat²; \\ Romeu Vianni ${ }^{3}$; José Francisco Maldonado ${ }^{4}$ \\ ${ }^{2}$ Centro de Ciências e Tecnologias Agropecuárias - UENF/CCTA/LFIT, Av. Alberto Lamego, 2000 - Horto \\ CEP: 28015620 - Campos dos Goytacazes, RJ. \\ ${ }^{3}$ Centro de Ciências e Tecnologias Agropecuárias - UENF/CCTA/LTA. \\ ${ }^{4}$ Estação Experimental da PESAGRO-Rio/Macaé - Estrada Velha de Glicério, Km 3 - CEP: 27901-970 - Macaé, RJ. \\ *Autor correspondente <marinho@uenf.br>
}

\begin{abstract}
RESUMO: O nitrogênio é um dos nutrientes cujo fornecimento está relacionado aos maiores aumentos na produtividade do mamoeiro. Entretanto, seu efeito sobre a qualidade dos frutos nem sempre tem se mostrado favorável. Com o objetivo de verificar o efeito de fontes e doses de nitrogênio sobre algumas características qualitativas dos frutos do mamoeiro (Carica papaya L.) cv. Improved Sunrise Solo Line 72/12, conduziu-se este trabalho. O experimento foi conduzido no campo, sobre um ARGISSOLO AMARELO, no primeiro ano da cultura, em delineamento de blocos casualizados. Foram estudadas três doses de N (10, 20 e $30 \mathrm{~g}$ planta $^{-1}$ mês $^{-1}$ ), e duas fontes de nitrogênio (sulfato de amônio e nitrato de amônio). Avaliaram-se o número de frutos por planta, o peso médio dos frutos, o pH, a acidez titulável, o teor de ácido ascórbico e os sólidos solúveis totais. $\mathrm{O}$ aumento das doses de $\mathrm{N}$ foi acompanhado por um aumento linear do número de frutos por planta. $\mathrm{O}$ peso médio dos frutos, o pH e o teor de ácido cítrico não foram afetados pelos tratamentos. $\mathrm{O}$ sulfato de amônio provocou um decréscimo linear dos sólidos solúveis totais com o aumento das doses de $\mathrm{N}$. A aplicação de nitrato de amônio promoveu maior produção de frutos com teor mais elevado de vitamina $\mathrm{C}$. Palavras-chave: Carica papaya, mamão, adubação nitrogenada, qualidade de fruto, ácido ascórbico
\end{abstract}

\section{NITROGEN SOURCES AND RATES, AND THE PAPAYA FRUIT QUALITY}

\begin{abstract}
Nitrogen supplement is related to the major increases in yield, its effects on fruit quality are however, unfavorable in many cases. With the aim of evaluating the effect of sources as well as rates of nitrogen fertilizer on the quality of papaya (cv. Improved Sunrise Solo Line 72/12') fruits, an experiment was carried out in field, using an Acrisol, in a randomized $2 \times 3$ complete factorial block design, with three replications. Three rates of $\mathrm{N}\left(10,20\right.$ and 30 g plant $^{-1}$ month $^{-1}$ ) with two sources of $\mathrm{N}$ (ammonium sulfate and ammonium nitrate), were applied to a total of 18 plants. Fruit number, weight, $\mathrm{pH}$, acidity, ascorbic acid and total soluble solids were determined. Increasing $\mathrm{N}$ rates caused an increase in fruit yield. Weight, $\mathrm{pH}$ and acidity were not affected by the treatments. Total soluble solids contents decreased when ammonium sulfate application increased. The treatment with ammonium nitrate resulted in higher fruit production, as well as increased ascorbic acid concentration.
\end{abstract}

Key words: papaya, nitrogen fertilization, fruit's quality, ascorbic acid

\section{INTRODUÇÃO}

A cultivar de mamão mais plantada no Brasil é a Improved Sunrise Solo, e seu fruto reúne as principais características preferidas pelo mercado, que são: ter origem de flores hermafroditas; conteúdo mínimo de 13 a $15 \%$ de sólidos solúveis totais; peso médio em torno de $500 \mathrm{~g}$; forma alongada; periforme ou oval e uniforme; casca lisa, sem nervuras ou manchas externas; frutos firmes, com polpa espessa, de coloração vermelhoalaranjada; cavidade redonda; amadurecimento lento e altos teores de açúcares (Luna, 1986).

$\mathrm{Na}$ composição química da polpa do mamão predominam água $(86,8 \%)$, açúcares $(12,18 \%)$ e proteínas $(0,5 \%)$. O fruto é considerado uma importante fonte de carotenóides, precursores da vitamina A, e bastante rico em vitamina C (Souza, 1998).
O nitrogênio é um dos nutrientes cujo fornecimento está relacionado aos maiores aumentos na produtividade do mamoeiro. Entretanto, seu efeito sobre a qualidade dos frutos nem sempre tem se mostrado favorável.

A tentativa de maximizar os lucros depara-se, muitas vezes, com o desafio de aumentar a produção sem interferir na qualidade do produto final. Dessa forma, aumentos na produção, proporcionados pelo emprego de fertilizantes, devem ser acompanhados pelo aumento ou manutenção da qualidade dos frutos produzidos.

Awada \& Long (1978) e Pérez-López \& ReysJurado (1983) observaram que o aumento do número de frutos produzidos, em função do aumento da adubação com nitrogênio, foi acompanhado por uma redução no peso e no tamanho dos mesmos. 
Fernandes et al. (1992) verificaram uma redução na porcentagem de sólidos solúveis na polpa do mamão em função de aumentos na taxa de adubação nitrogenada. No entanto, Viégas (1997) observou um aumento da produção de frutos em função da adubação nitrogenada sem que houvesse perdas de peso ou diminuição na porcentagem de sólidos solúveis totais do fruto.

Embora, na literatura, existam vários registros sobre o efeito de doses de adubos nitrogenados no aumento dos frutos produzidos, há pouca informação disponível sobre o efeito dessas fontes sobre as características de qualidade dos mesmos.

O objetivo desse trabalho foi avaliar o efeito de fontes e doses de nitrogênio sobre algumas características relativas a qualidade dos frutos do mamoeiro 'Improved Sunrise Solo Line 72/12'.

\section{MATERIAL E MÉTODOS}

O experimento foi conduzido na Empresa de Pesquisa Agropecuária do Rio de Janeiro, Estação Experimental de Fruticultura de Macaé-RJ, num ARGISSOLO AMARELO, durante o período de agosto de 1997 a julho de 1998.

A estação encontra-se a uma altitude de 4 metros, latitude de $22^{\circ} 24^{\prime} 58^{\prime \prime}$ e longitude de $41^{\circ} 42^{\prime} 30^{\prime \prime}$. Apresenta temperatura média máxima de $28^{\circ} \mathrm{C}$, média mínima de $19,5^{\circ} \mathrm{C}$, precipitação pluviométrica de 1244 $\mathrm{mm}$ anuais e umidade relativa de $81,1 \%$. A cultivar utilizada foi a Improved Sunrise Solo 72/12 que, atualmente, ocupa cerca de $75 \%$ da área cultivada com mamoeiro no Estado do Espírito Santo, produzindo em média $40 \mathrm{t} \mathrm{ha}^{-1} \mathrm{ano}^{-1}$, com início da produção do oitavo ao nono mês, frutos pesando em média $405 \mathrm{~g}$. As mudas foram produzidas sob ripado, em sacos de polietileno pretos $(23 \times 12 \mathrm{~cm})$, preenchidos com substrato constituído de terra arenosa e esterco de curral curtido, na proporção de 3:1. Ao substrato foram adicionados superfosfato simples e cloreto de potássio, nas doses de 2,5 e $1 \mathrm{~kg} \mathrm{~m}^{-3}$ de substrato, respectivamente.

As mudas foram transferidas para a área experimental quando atingiram a altura de $20 \mathrm{~cm}$. $O$ plantio foi efetuado em fileiras duplas no espaçamento de 3,6 m entre linhas duplas e 2,0 m entre plantas em 01 de agosto de 1997.

O preparo do solo, com uma aração, a aplicação do calcário ( $\left.1 \mathrm{t} \mathrm{ha}^{-1}\right)$ e a gradagem foram realizados 60 dias antes do transplantio. Foram plantadas três mudas por cova (dimensões de $50 \times 30 \times 30 \mathrm{~cm}$ ). Após o desbaste, efetuado após a sexagem das plantas aos quatro meses após o transplantio, permaneceu apenas uma planta hermafrodita por cova.

Foram aplicados na cova de plantio, $15 \mathrm{~L}$ de esterco de curral curtido, $200 \mathrm{~g}$ de calcário dolomítico, $400 \mathrm{~g}$ de superfosfato simples, $50 \mathrm{~g}$ de cloreto de potássio e $20 \mathrm{~g}$ da formulação FTE BR 12 contendo boro, cobre, ferro, manganês, molibdênio e zinco.
Utilizou-se o delineamento experimental em blocos casualizados, em esquema fatorial no qual foram estudadas duas fontes nitrogenadas (sulfato de amônio e nitrato de amônio) em três doses (10, 20 e $30 \mathrm{~g}_{\text {planta }}{ }^{-1}$ mês $^{-1}$ de N) com três repetições. A parcela experimental foi composta por oito plantas $\left(44,8 \mathrm{~m}^{2}\right)$ das quais quatro foram avaliadas.

Foram realizadas adubações mensais com sulfato de potássio e bimestrais com superfosfato simples para fornecer, em cada aplicação, $20 \mathrm{~g}$ de $\mathrm{K}_{2} \mathrm{O}$ e $8 \mathrm{~g}$ de $\mathrm{P}_{2} \mathrm{O}_{5}$ por planta, respectivamente.

As adubações foram efetuadas acompanhando a linha da copa em faixas de $20 \mathrm{~cm}$ de largura e a aplicação foi alternada entre o lado de cima e o lado de baixo de uma mesma linha a cada mês. As plantas foram submetidas aos tratamentos um mês após o transplantio das mudas. A área foi irrigada por um sistema de microaspersão com a aplicação de uma lâmina diária de $7 \mathrm{~mm}$.

Avaliaram-se o número de frutos por planta, o peso médio, o $\mathrm{pH}$, a acidez titulável, o teor de ácido ascórbico e os sólidos solúveis totais dos frutos. A produção de frutos no primeiro ano foi avaliada por meio da contagem direta dos frutos na planta aos nove meses a qual, segundo Marin et al. (1995), pode ser usada como critério de produtividade. O número de frutos na planta aos nove meses foi utilizado, juntamente com o peso médio dos frutos na época da colheita, para estimar a produção média por hectare para o primeiro ano de cultivo.

O peso médio dos frutos foi obtido por meio da pesagem individual de cada fruto, duas vezes por semana, após o início da colheita (30 de março de 1998) até 20 de julho de 1998, quando foi estimada a produção média de frutos.

Para as análises químicas os frutos foram amostrados em março de 1998, quando apresentavam a casca verde claro e com duas estrias amareladas longitudinais, partindo da base do fruto até o pedúnculo. Este ponto de colheita, segundo Souza (1998), é o mais utilizado para o mercado interno e externo. Nessa ocasião foram colhidos quatro frutos por parcela. As análises foram efetuadas na polpa triturada por um liquidificador doméstico, marca Arno, modelo LE, por 30 segundos na velocidade " 3 ", sem a casca e sem as sementes.

$\mathrm{O} \mathrm{pH}$ foi determinado por meio de leitura direta na polpa triturada, utilizando-se um pHmetro portátil marca WTW tipo pH 320. A acidez titulável, expressa em g de ácido cítrico por $100 \mathrm{~g}$ de polpa, foi determinada a partir de uma alíquota de $5 \mathrm{~mL}$ da polpa triturada e centrifugada, usando-se o indicador fenolftaleína e titulação com $\mathrm{NaOH} 0,1 \mathrm{~N}$. O teor de ácido ascórbico expresso em mg por $100 \mathrm{~g}$ de polpa, foi obtido por titulação com solução de 2,6 dinitrofenilhidrazina (2,6 D) de acordo com o método 43.064, descrito na Association of Official Analytical Chemistry (1984).

Foram retiradas, mensalmente, de dezembro de 1997 a abril de 1998, amostras de folhas para análise de nutriente ( $\mathrm{N}$ orgânico, $\mathrm{N}^{-\mathrm{NO}_{3}}{ }_{3}^{-} \mathrm{P}, \mathrm{K}, \mathrm{Ca}, \mathrm{Mg}, \mathrm{S}, \mathrm{B}$, $\mathrm{Fe}, \mathrm{Mn}$ e $\mathrm{Zn}$ ), de acordo com metodologias descritas por 
Malavolta et al. (1997) e Jones Júnior. et al. (1991). As aplicações constantes de fungicidas cúpricos impediram a determinação precisa do $\mathrm{Cu}$, sendo o mesmo, por esta razão, excluído das análises.

Neste trabalho serão apresentadas apenas as médias dos teores de nutrientes, no limbo foliar, para as duas fontes nitrogenadas. A folha amostrada foi a recém - madura, caracterizada por apresentar uma flor recémaberta em sua axila (Viégas, 1998). As amostragens de folhas foram efetuadas sempre no período da manhã, entre 9 e $11 \mathrm{~h}$.

Foram testados os modelos lineares para as doses de $\mathrm{N}$ por meio de análises de regressões. As fontes de nitrogênio foram comparadas pelo teste $\mathrm{F}$ a 5 e $1 \%$.

\section{RESULTADOS E DISCUSSÃO}

O número de frutos por planta, aos nove meses, aumentou linearmente com $\mathrm{O}$ aumento das doses de $\mathrm{N}$ aplicadas (TABELA 1). Nas doses de 10 e $30 \mathrm{~g}$ planta $^{-1}$ mês ${ }^{-1}$ de $\mathrm{N}$ as plantas adubadas com nitrato de amônio apresentaram um maior número de frutos em relação àquelas adubadas com sulfato de amônio.

Não foi observado efeito dos tratamentos sobre o peso médio dos frutos (TABELA 1). Viégas (1997) também não verificou efeito de doses de $\mathrm{N}$ sobre 0 tamanho dos frutos do mamoeiro.

O peso médio dos frutos (TABELA 1), entretanto, apresentou-se menor que o de $405 \mathrm{~g}$ citado por Marin et al. (1995) para essa cultivar. O menor peso observado parece ter sido conseqüência da época restrita de colheita, entre março a julho. Segundo o mesmo autor, frutos colhidos no inverno (em torno de maio a setembro) são maiores que os colhidos em outras épocas. Neste experimento a época de colheita coincidiu com a época prevista para colheita de frutos de menor peso.

A maior produtividade estimada $\left(33,5 \mathrm{t} \mathrm{ha}^{-1}\right)$ foi atingida com a dose de $30 \mathrm{~g}_{\text {planta }}{ }^{-1} \mathrm{mês}^{-1}$ de $\mathrm{N}$ com a aplicação do nitrogênio na forma de nitrato de amônio, que corresponde a $360 \mathrm{~g}$ planta $^{-1}$ ano $^{-1}$ de N (TABELA 2).

Fernandes et al. (1992), Hajardi et al. (1995) e Viégas (1997), recomendam, para o mamoeiro, as doses de 375,473 e 332 g planta $^{-1} a^{-1}$ de N, respectivamente.

Não houve efeito dos tratamentos sobre o pH ou sobre a acidez (TABELA 3) . O teor médio de sólidos solúveis encontrados situa-se na faixa de teor citada por Luna (1986) para a Improved Sunrise Solo.

O aumento da dose de N, aplicado sobre a forma de nitrato de amônio, promoveu o aumento do número de frutos (TABELA 1) sem diminuir o teor de sólidos solúveis (TABELA 3). Entretanto, quando a fonte de nitrogênio empregada foi o sulfato de amônio, o aumento da dose de $\mathrm{N}$, também, promoveu o aumento do número de frutos (TABELA 1) mas foi observada uma redução linear na porcentagem de sólidos solúveis (modelo linear significativo a $1 \%$ de probabilidade) (TABELA 3). Viégas (1997) observou um aumento da produção de frutos em função do aumento da adubação nitrogenada, sem que houvesse queda na porcentagem de sólidos solúveis totais, utilizando a uréia como fonte de N.

Pereira et al. (1994) observou que a proporção entre $\mathrm{K}_{2} \mathrm{SO}_{4}$ e $\mathrm{KCl}$ utilizada em solução nutritiva interferiu na concentração de açúcar da uva. Estes resultados indicam efeitos do ânion acompanhante sobre a concentração final de sólidos solúveis nos frutos e demonstram a importância da fonte de adubo para a qualidade dos mesmos.

O teor de ácido ascórbico na polpa dos frutos foi maior nas plantas adubadas com nitrato de amônio em todas as doses de N aplicadas (TABELA 3). Somers \& Kelly (1951), observaram que em folhas de brócolis, infiltrações com sulfato de amônio diminuíram a taxa de acúmulo de ácido ascórbico e que o nitrato de amônio não apresentou influência sobre essa taxa. Esses autores verificaram, ainda, que o acúmulo de ácido ascórbico foi reduzido por sais de amônio, de modo geral, mas que a magnitude desse efeito foi determinada pelo ânion acompanhante. Via de regra, cloretos e sulfatos reduziram mais esse acúmulo do que nitratos. De acordo com esses autores, o efeito adverso do sulfato de amônio sobre o conteúdo de ácido ascórbico nas plantas é devido ao efeito deste sal na síntese e não sobre o catabolismo desta vitamina no tecido das plantas.

TABELA 1 - Número de frutos por planta, aos nove meses após o transplantio, e peso médio dos frutos na colheita, no primeiro ano de plantio do mamoeiro, em função das fontes e doses de $\mathrm{N}$.

\begin{tabular}{|c|c|c|c|c|}
\hline \multirow[t]{2}{*}{ Dose de N } & \multicolumn{2}{|c|}{$\begin{array}{l}\text { Número de frutos } \\
\text { por planta }\end{array}$} & \multicolumn{2}{|c|}{$\begin{array}{l}\text { Peso médio dos } \\
\text { frutos }\end{array}$} \\
\hline & $\begin{array}{l}\text { Sulfato } \\
\text { de } \\
\text { Amônio }\end{array}$ & $\begin{array}{c}\text { Nitrato } \\
\text { de } \\
\text { Amônio }\end{array}$ & $\begin{array}{l}\text { Sulfato } \\
\text { de } \\
\text { Amônio }\end{array}$ & $\begin{array}{l}\text { Nitrato } \\
\text { de } \\
\text { Amônio }\end{array}$ \\
\hline g planta-1 mês $^{-1}$ & & & ---------- & $\cdots$ \\
\hline 10 & $34,1 \mathrm{~b}$ & $43,0 \mathrm{a}$ & $317,75 a$ & $306,62 \mathrm{a}$ \\
\hline 20 & $45,4 \mathrm{a}$ & $45,7 \mathrm{a}$ & $315,25 \mathrm{a}$ & $316,97 \mathrm{a}$ \\
\hline 30 & $44,9 \mathrm{~b}$ & $57,9 a$ & $316,22 \mathrm{a}$ & $321,00 \mathrm{a}$ \\
\hline Linear & * & ** & ns & $\mathrm{ns}$ \\
\hline
\end{tabular}

As letras comparam as médias entre as fontes de N. Médias seguidas de mesma letra não diferem pelo teste $\mathrm{F}$ a $5 \%$. Modelo linear testado para as doses de $\mathrm{N}$ a $1 \%\left({ }^{* *}\right)$ ou a $5 \%\left({ }^{*}\right)$.

TABELA 2 - Produção estimada do mamoeiro, em toneladas por hectare, no primeiro ano de plantio em função das fontes e doses de $\mathrm{N}$.

\begin{tabular}{ccc}
\hline \multirow{2}{*}{ Dose de N } & \multicolumn{2}{c}{ Produtividade } \\
\cline { 2 - 3 } & Sulfato de amônio Nitrato de amônio \\
\hline g planta $^{-1}$ mês $^{-1}$ & --------- \\
10 & $19,7 \mathrm{~b}$ & $24,9 \mathrm{a}$ \\
20 & $26,3 \mathrm{a}$ & $26,4 \mathrm{a}$ \\
30 & $26,0 \mathrm{~b}$ & $33,5 \mathrm{a}$ \\
\hline Linear & ${ }^{*}$ & ${ }^{*}$ \\
\hline
\end{tabular}

As letras comparam as médias entre as fontes de N. Médias seguidas de mesma letra não diferem pelo teste $\mathrm{F}$ a $5 \%$. Modelo linear testado para as doses de $\mathrm{N}$ a $1 \%\left({ }^{* *}\right)$ ou a $5 \%\left(^{*}\right)$. 
TABELA 3 - Atributos químicos dos frutos do mamoeiro 'Solo' colhidos em março de 1998, em função das fontes e dose de N.

\begin{tabular}{|c|c|c|c|c|c|c|c|c|}
\hline \multirow[t]{2}{*}{ Dose de $\mathrm{N}$} & \multicolumn{2}{|c|}{$\mathrm{pH}$} & \multicolumn{2}{|c|}{ Sólidos Solúveis Totais } & \multicolumn{2}{|c|}{ Ácido cítrico } & \multicolumn{2}{|c|}{ Ácido ascórbico } \\
\hline & $\begin{array}{l}\text { S. de } \\
\text { amônio }\end{array}$ & $\begin{array}{c}\text { N. de } \\
\text { amônio }\end{array}$ & $\begin{array}{l}\text { S. de } \\
\text { amônio }\end{array}$ & $\begin{array}{c}\text { N. de } \\
\text { amônio }\end{array}$ & $\begin{array}{l}\text { S. de } \\
\text { amônio }\end{array}$ & $\begin{array}{c}\text { N. de } \\
\text { amônio }\end{array}$ & $\begin{array}{l}\text { S. de } \\
\text { amônio }\end{array}$ & $\begin{array}{c}\text { N. de } \\
\text { amônio }\end{array}$ \\
\hline g planta ${ }^{-1}$ mês $^{-1}$ & & & ----------- & --------- & g 100 & e polpa & g 100 & e polpa \\
\hline 10 & $5,41 \mathrm{a}$ & $5,36 \mathrm{a}$ & $15,7 \mathrm{a}$ & $14,2 b$ & $0,057 \mathrm{a}$ & $0,063 \mathrm{a}$ & $84,9 \mathrm{~b}$ & $92,5 \mathrm{a}$ \\
\hline 20 & $5,34 \mathrm{a}$ & $5,41 \mathrm{a}$ & $14,3 \mathrm{a}$ & $15,2 \mathrm{a}$ & $0,070 \mathrm{a}$ & $0,063 \mathrm{a}$ & $87,2 \mathrm{~b}$ & 96,0 a \\
\hline 30 & $5,36 \mathrm{a}$ & $5,35 \mathrm{a}$ & $14,2 \mathrm{a}$ & $14,8 \mathrm{a}$ & $0,067 \mathrm{a}$ & $0,070 \mathrm{a}$ & $88,3 \mathrm{~b}$ & $96,8 \mathrm{a}$ \\
\hline Linear & ns & ns & ** & ns & ns & ns & ns & ns \\
\hline
\end{tabular}

As letras comparam as médias entre as fontes de N. Médias da mesma característica seguidas de mesma letra não diferem pelo teste $\mathrm{F}$ a $5 \%$ de probabilidade para pH, SST e ácido cítrico e 1\% para ácido ascórbico. Modelo linear significativo a 1\% ( $\left.{ }^{*}\right)$ ou não significativo a 5\% (ns).

TABELA 4 - Teor médio de nutrientes, na matéria seca do limbo foliar da folha recém-madura do mamoeiro em função das fontes de $\mathrm{N}$ utilizadas (Média de cinco épocas de amostragem).

\begin{tabular}{|c|c|c|c|}
\hline \multirow[t]{2}{*}{ Nutrientes } & & \multicolumn{2}{|c|}{ Fonte de $\mathrm{N}$} \\
\hline & & Sulfato de amônio & Nitrato de amônio \\
\hline $\mathrm{N}$ & $\mathrm{g} \mathrm{kg}^{-1}$ & $43.0 \mathrm{a}$ & $43.5 \mathrm{a}$ \\
\hline $\mathrm{NO}_{3}^{-}$ & & $0.70 \mathrm{a}$ & $0.70 \mathrm{a}$ \\
\hline$P$ & & $4.79 \mathrm{a}$ & $4.82 \mathrm{a}$ \\
\hline $\mathrm{K}$ & & $21.2 \mathrm{a}$ & $20.6 \mathrm{a}$ \\
\hline $\mathrm{Ca}$ & & $15.3 \mathrm{a}$ & $15.5 \mathrm{a}$ \\
\hline $\mathrm{Mg}$ & & $8.56 \mathrm{a}$ & $8.95 \mathrm{a}$ \\
\hline$S$ & & $5.65 \mathrm{a}$ & $5.29 \mathrm{~b}$ \\
\hline$B$ & $\mathrm{mg} \mathrm{kg}^{-1}$ & $50.9 a$ & $49.6 \mathrm{a}$ \\
\hline $\mathrm{Fe}$ & & $147 a$ & $149 a$ \\
\hline $\mathrm{Zn}$ & & $25.4 \mathrm{a}$ & $25.3 \mathrm{a}$ \\
\hline $\mathrm{Mn}$ & & $98.5 \mathrm{a}$ & $87.9 \mathrm{a}$ \\
\hline
\end{tabular}

As letras comparam as médias entre as fontes. Médias seguidas de mesma letra não diferem pelo teste $\mathrm{F}$ a $5 \%$.

As plantas adubadas com sulfato de amônio apresentaram maior teor de $S$ no tecido do limbo (TABELA 4). Este resultado deve-se à presença desse nutriente no sulfato de amônio na concentração de 22 a $24 \mathrm{~g} \mathrm{~kg}^{-1} \mathrm{e}$ à sua ausência no nitrato de amônio (Raij et al., 1997). Os teores médios de nitrato, não foram influenciados pela fonte de $\mathrm{N}$ aplicada. $\mathrm{O}$ nitrogênio absorvido na forma nítrica é prontamente reduzido à amônio pelas plantas, uma vez que seu acúmulo provoca toxidez. O nitrogênio na forma de amônio, absorvido nessa forma ou resultante da redução do nitrato, é assimilado pelas plantas e incorporado na forma de aminoácidos e proteínas (Malavolta et al., 1997). Desse modo, a forma de nitrogênio fornecida nem sempre promove diferenças detectáveis na concentração final de nitrato nos tecidos das plantas.

\section{AGRADECIMENTO}

À PESAGRO-Rio, Estação experimental de Fruticultura de Macaé, pela infra-estrutura cedida para instalação do experimento e pelo apoio na sua condução.

\section{REFERÊNCIAS BIBLIOGRÁFICAS}

ASSOCIATION OF OFFICIAL ANALYTICAL CHEMISTRY. Official methods of analysis. Washington: AOAC, 1984. 10150p.

AWADA, M.; LONG, C.R. Relation of nitrogen and phosphorus fertilization to fruiting and petiole composition of 'Solo' papaya. Journal of the American Society for Horticultural Science, v.103, p.217-219, 1978.

FERNANDES; D.M.; CORREA, L.S.; FERNANDES, F.M. Efeito da Adubação nitrogenada e fosfatada em mamoeiro (Carica papaya L.) 'Solo' cultivado com irrigação. Científica, v.18, p.1-8, 1992.

HAJARDI, S.S.; FILOSA, I.P.; SUTRISNO, K. The effect of K levels on the yield and quality of fruit and crude papain from 3 papaya cultivars. Acta Horticulture, v.1, p.83-88, 1995.

JONES JÚNIOR., J.B.; WOLF, B.; MILLS, H.A. Plant analysis handbook: a practical sampling, preparation, analysis, and interpretation guide. Athens: MicroMacro, 1991. 213p.

LUNA, J.V.U. Variedades de mamoeiro. Informe Agropecuário, v.12, p.14-18, 1986.

MALAVOLTA, E., VITTI, G.C., OLIVEIRA, S.A. DE. Avaliação do estado nutricional das plantas: princípios e aplicações. 2.ed. Piracicaba: Potafós, 1997. 319p.

MARIN, S.L.D., GOMES, J.A., SALGADO, J.S., MARTINS, D.S., FULLIN, E.A. Recomendações para a cultura do mamoeiro dos grupos 'Solo' e "Formosa" no Estado do Espírito Santo. 4.ed. Vitória: EMCAPA, 1995. 57p. (Circular Técnica, 3).

PEREIRA, F.M.; COUTINHO, E.L.M.; OLIVEIRA, F.Z. Importância da adubação na qualidade das frutas de clima temperado. In: SÁ, M.E. DE; BUZZETI, S.(Ed.) Importância da adubação na qualidade dos produtos agrícolas. São Paulo: Ícone, 1994. cap.10, p.161- 176

PÉREZ-LOPEZ, A.; REYS-JURADO, R.D. Effect of nitrogen and boron aplication on Carica papaya L. I. Growth and Yield. Journal of Agriculture of the University of Puerto Rico, v.67, p.287-291, 1983.

RAIJ, B. VAN; CANTARELLA, H.; QUAGIO, J.A.; FURLANI, A.M.C. Recomendações de adubação e calagem para o estado de São Paulo. 2.ed. Campinas: IAC, 1997. 285p. (Boletim Técnico, 100).

SOMERS, G.F.; KELLY, W.C. Ascorbic acid and dry matter accumulation in turnip and broccoli leaf discs after infiltration with inorganic salts, organic acids and some enzyme inhibitors. Plant Physiology, p.90-107, 1951.

SOUZA, G. DE Características físicas, químicas e sensoriais do fruto de cinco cultivares de mamoeiro (Carica papaya L.) produzidas em Macaé-RJ. Campos dos Goytacazes, 1998. 87p. Dissertação (Mestrado) - Universidade Estadual do Norte Fluminense.

VIÉGAS, P.R.A. Teores de nitrogênio em tecidos foliares, produção e qualidade de frutos de mamoeiro, em função da adubação nitrogenada. Viçosa, 1997. 62p. Tese (Doutorado) Universidade Federal de Viçosa.

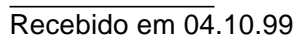

